University of Nebraska - Lincoln

DigitalCommons@University of Nebraska - Lincoln

Textile Society of America Symposium

Proceedings

Textile Society of America

2020

\title{
Unseen, unheard, unnamed: The matchless and unsung heroes of the textile art and craft of Rajasthan
}

Simrita Singh

Anu H. Gupta

Follow this and additional works at: https://digitalcommons.unl.edu/tsaconf

Digitalrt of the Art and Materials Conservation Commons, Art Practice Commons, Fashion Design

Commens, Fiber, Textile, and Weaving Arts Commons, Fine Arts Commons, and the Museum Studies

detwerkns

Logo

This Article is brought to you for free and open access by the Textile Society of America at

DigitalCommons@University of Nebraska - Lincoln. It has been accepted for inclusion in Textile Society of America

Symposium Proceedings by an authorized administrator of DigitalCommons@University of Nebraska - Lincoln. 


\section{Unseen, unheard, unnamed: The matchless and unsung heroes of the textile art and craft of Rajasthan}

Simrita Singh and Anu H. Gupta

Singhsimrita@hotmail.com guptaanupu@gmail.com

\section{The Glorious Textile Heritage of India}

Textile Art is defined as anything created or woven entirely by hand or using just basic tools. These are items of usefulness and adornment created with a wide range of creative and design activities including work with textiles, metal, stones, paper etc. The history of textile art in India is ancient, dating back almost 5000 years. The first surviving written references in the Indian subcontinent can be positioned in Indus Valley civilization (3000-1700 BC). The excavated artefacts reflect the wide-ranging and intense moods of our culture and heritage. These pieces of handicraft are distinguished for their great functional and aesthetic value through the creative usage of fascinating colours, motifs, patterns and designs and are a reflection of the glorious Indian traditions and culture. From the period of the Indus Valley Civilization until the present, the cultural landscape has experienced significant and subtle incorporations, adaptations, and adoptions of unique cultural and aesthetic features.

\section{Diversity in Indian Textiles}

Since ancient times, this land has piqued the interest of travellers, visitors, rulers and invaders from all over the world and across the oceans. There is evidence on the floor of the Indus Valley indicating trade ties between Mesopotamia, Egypt, and other distant lands, particularly cotton and textiles. These commercial ties may be traced back to the Mughal, Portuguese, and British colonial empires that were established in India. There were special warehouses built near ports in various regions of India, where the ruling dynasties had tie-ups with Indian craftsmen to make artistic goods to their taste and requirements. These age-old traditions and legacy of handcrafted textiles have paved way for today's highly advanced and popular textiles crafted in a variety of styles and techniques.

India has marvelous artisans and craftsmen, skilled in producing handicraft items that serve a utilitarian function with an element of art or ornamentation or decoration. This creation with the hand and the creative imagination has established India as a major manufacturer and supplier of handicrafts to the worldwide market. The creation of Indian handicrafts is distributed across the country in both rural and urban regions, and numerous artisans are engaged in crafts work. Today, too, worldwide connections have introduced, impacted and influenced new artistic concepts and trends, resulting in a need for unique artisan crafted products. This interchange has affected the craftsman and its craft, as well as producers and customers, beyond the bounds of cultural group. These cross-cultural encounters serve as motivation for craftsmen and craftspeople for drawing inspiration and hence producing much marketable and saleable craft items. One such craft is 'blue pottery'. The name 'blue pottery' comes from the "royal blue" coloured dye used in the pottery. This craft is an example of cross-cultural interactions and influences. 

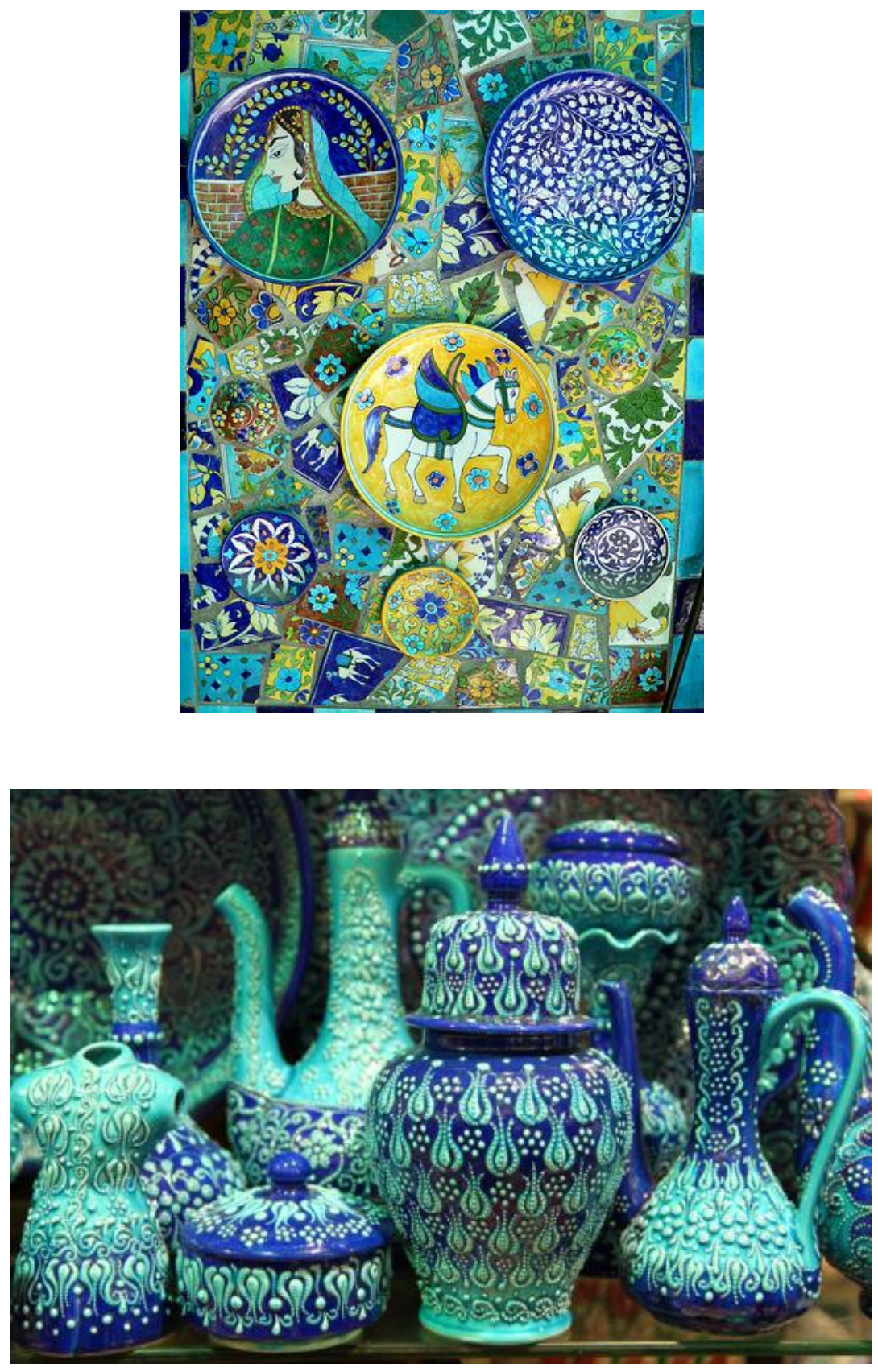

Plate1: Blue pottery- A very popular craft of Rajasthan

Textile art and handicraft in India are also essential cultural elements that have links to the past while creating the future. This is particularly true as skill is given a significant place especially in rural and tribal Indian communities. The diversity of India's textile art abilities makes it a 
treasure trove of creative inspiration for the present designers. The handicrafts bind together traditions and culture of a community. These artisans have a significant role in passing down traditions and rites to future generations through traditional handicrafts and fabrics, which are required for weddings, births, deaths, and festivals etc. Majority of the Indian textile crafts are related to the geographical locations reflecting and emphasizing the regional flavour and distinctiveness. Durga Puja in Bengal, Onam in south, Teej in Rajasthan and Garba festivities during Navratri in Gujarat and Baisakhi in Punjab are all incomplete without a touch of traditionally woven, crafted or decorated textiles.

The present paper discusses and deliberates on various traditional crafts of Rajasthan and how the craftsperson are preserving them. It also emphasizes their status and situation, in which, despite their commitment to preserving the cultural legacies of the crafts and the state, they largely remain invisible and unnoticed.

\section{The Culture and Textile Traditions of Rajasthan}

Rajasthan is known for its exquisite handicrafts especially the textiles such as Lehariya, Bandhini, Gota Patti and Block Printing. Bandhini is a term which in local dialect called bandhej means 'badhi hui' or tied up. Various patterns are created by tying base cloth with thread and overdyeing it with vivid colours resulting in a multipatterned and multihued fabric ready to use as a drape or to be stitched. This fabric is called as Badhini. Lehariya is also developed by using the same technique producing diagonal striped patterns in single or multi colour. This craft is practiced all over Rajasthan primarily in Jodhpur and Jaipur.

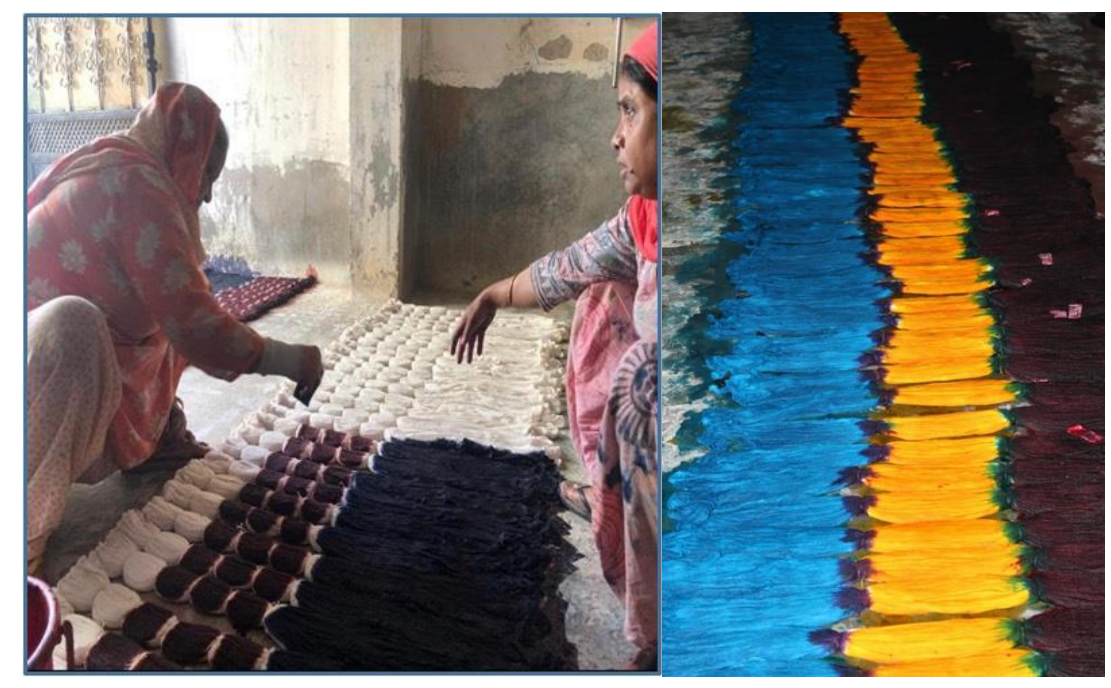

Plate 2: Artisans preparing tie and dye fabric (left) and dyed fabric (right) 


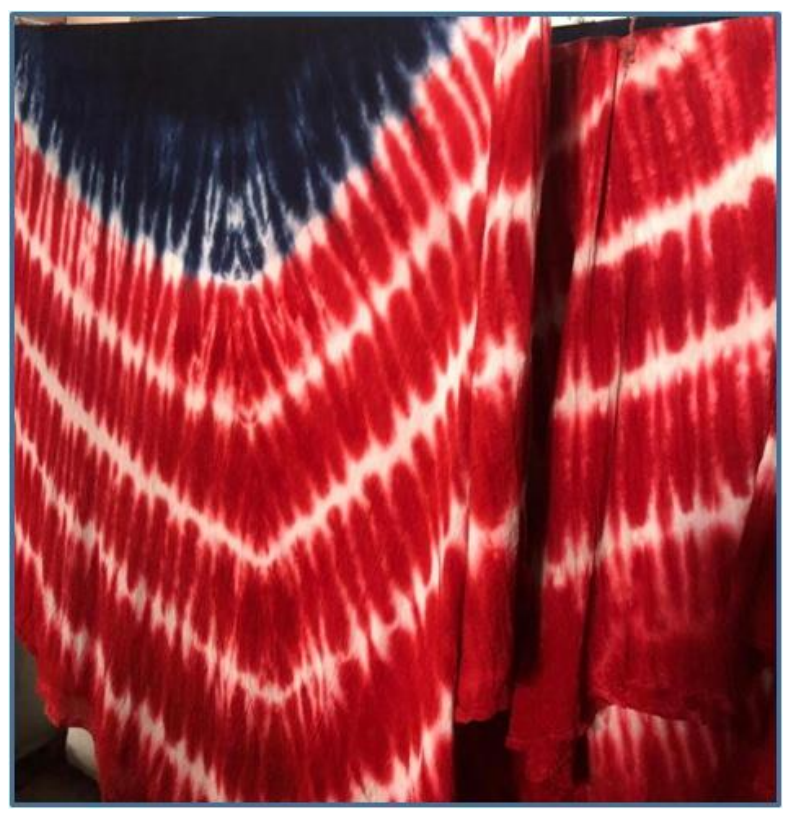

Plate 3: Fabric with tie and dye crafted effect

Gota Patti is a rich embroidered craft in which small petal shaped pieces commonly known as Pattis are cut out of a traditional shiny golden ribbon called gota. These pattis or petals are crafted in a composition to create intricate floral patterns. These patterns are embroidered and spread over traditional garments of Rajasthan like sarees, ghagra cholis and odhanis. Now a days a lot of products and accessories can be found in Gota patti work. Earlier Gota was made out of pure gold but at present synthetic gota is used for the craft. Not only golden but this embroidery is also made using in silver, bronze ,copper, rose gold gota.

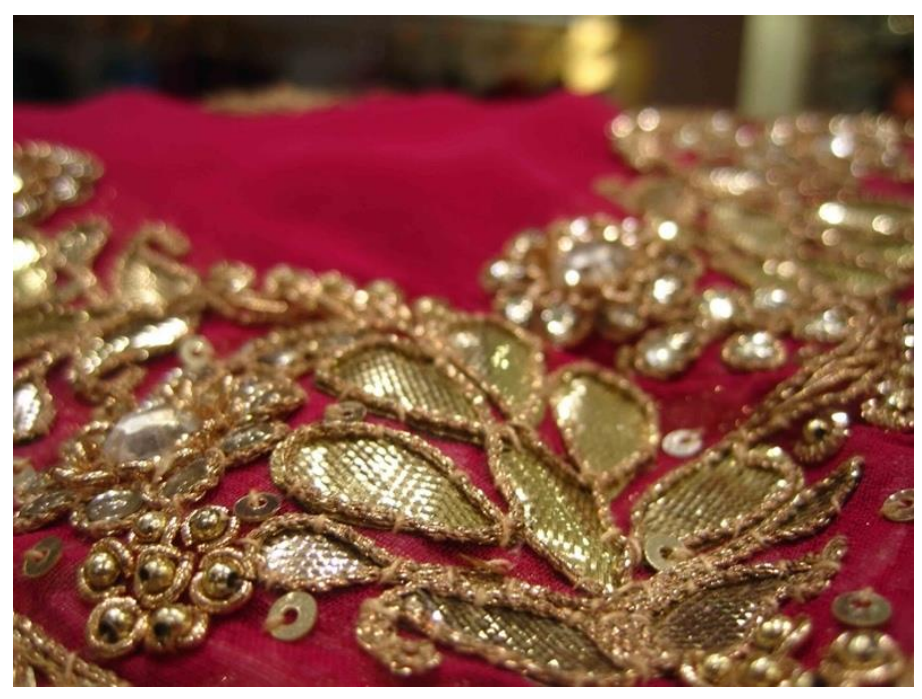

Plate 4: Gota Patti work 
The base fabric is stretched on an adda or a large embroidery frame. This base is already printed with the pattern and design where gota and other accessories are applied or put together. Gota is cut into the desired shapes and sizes as per the motif or design to be worked on the base fabric. The number of artisans or craftspersons involved in this surface enrichment technique depends upon the length of the base fabric, product and the area to be embroidered or embellished with gota patti. They sit on the floor, around the frame and work with a crewel needle and fine thread . The work of gota patti is combined with many other stiches or embroidery. This craft is popularly and primarily practiced in a village called Nyla near Jaipur.

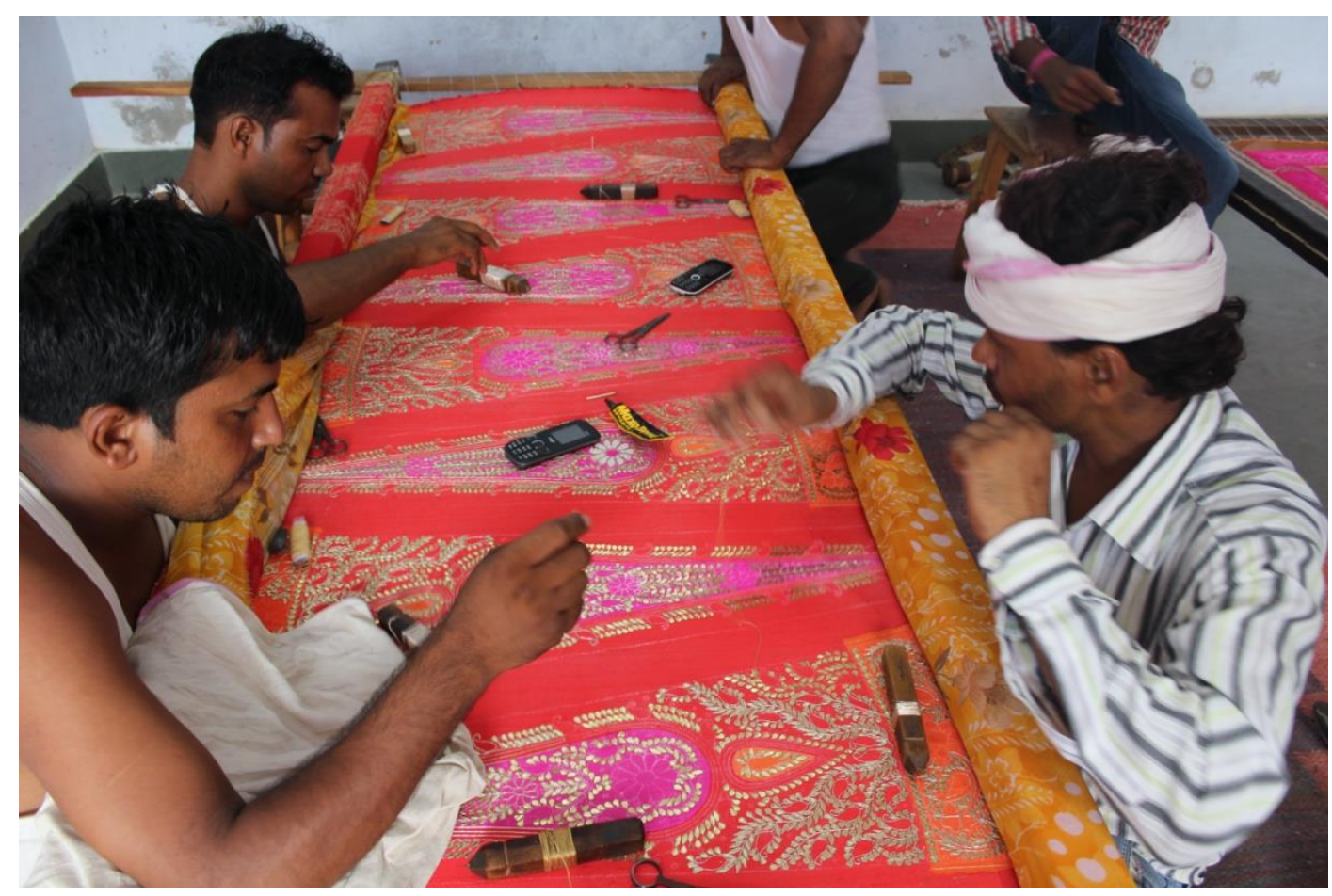

Plate 5: Fabric stretched over a frame and artisans embroidering Gota Patti

Hand-block printing is an integral element of Rajasthan's traditional history. As the name implies, this technique entails hand printing using etched or engraved wooden blocks. Wooden blocks are made out of raw wood pieces by special artisans or block makers. Motifs of flora and fauna are prominent in Block printing. Along with this, geometrical shapes, human figures, everyday life scenes etc. are carved on the blocks to be printed on variety of surfaces ranging from garments to home furnishing and other life style products and accessories. 


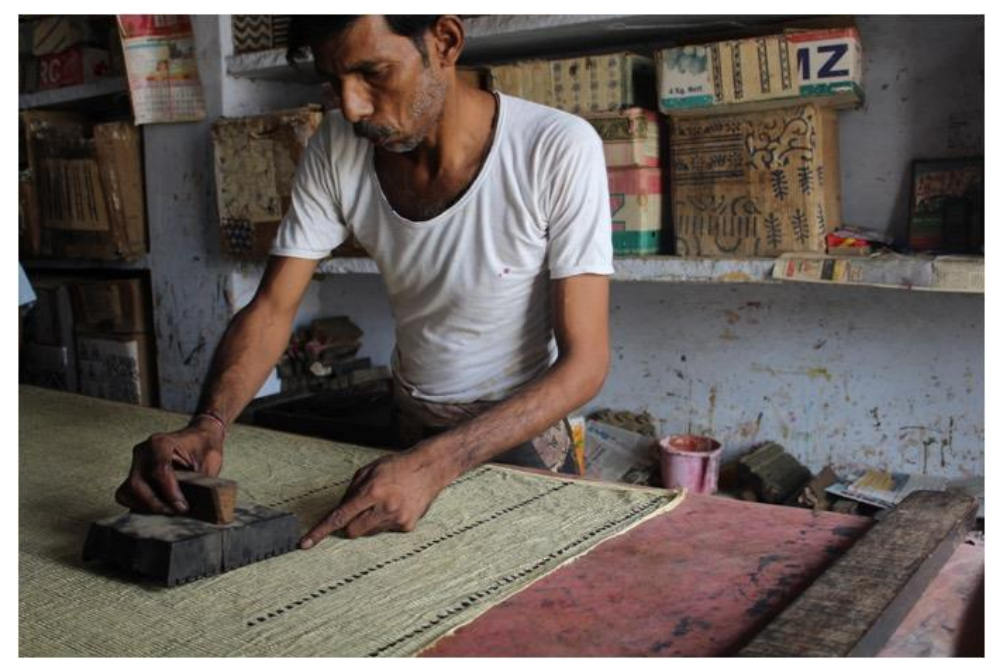

Plate 6: Artisan printing fabric with a Block

There are special padded long tables which are used for block printing. The fabric to be printed is laid flat on these tables. These block printers or craftsmen ensure that the cloth to be printed is wrinkle-free and is properly stretched. Printing paste made of pigments is first prepared and then placed on a pad that works similarly to a stamp pad. The block is then dipped in this printing paste before being stamped on the designated area of the base cloth with even pressure thrusted for each stamping. This is a tedious and an elaborate process because every motif is to be stamped individually and continuously by the artisan and it is the artisan's ability in stamping that makes it demand higher and ultimately fetches the artisan a good price.

The block print motifs can be single, double or multicoloured. The two-color or multicolored patterns include printing the same area with extreme care and accuracy over and over again. Bagru and Sanganer, both near Jaipur, are well-known for preserving this traditional art heritage of block printing. Sanganeri block printing is printed usually on a white backdrop, whereas Bagru block printing is done on a black and red background. Dabu is another type of block printing in which indigo dye is used for printing, and it is popularly known to be done in a small village near Jaipur called Bagru.

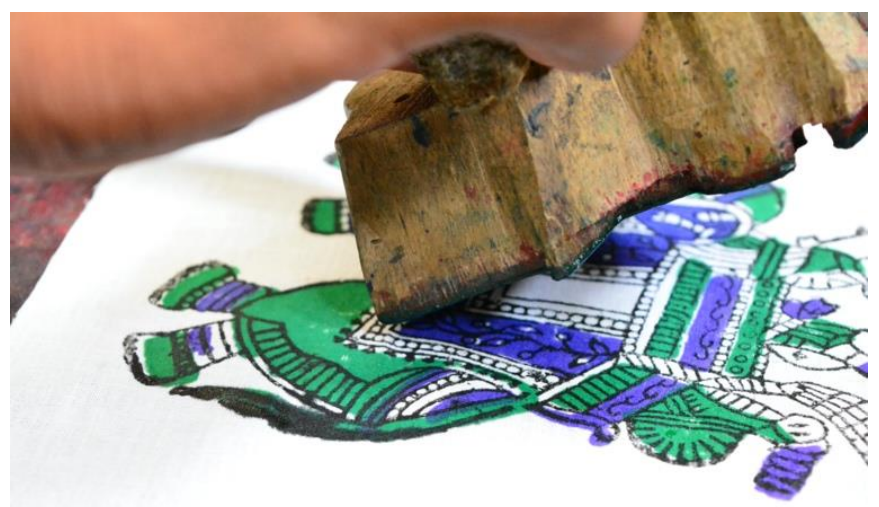

Plate 7: Multi Block Printing 


\section{The Unsung Creators}

Rajasthan is one of the important producers and suppliers of handicrafts to the global market. It's important to mention that artisans, designers work hand in hand to take this craft to a new level. They have played a vital role in revival, restoration and upliftment of many handicrafts of Rajasthan. These valuable, priceless and precious traditions of handicrafts live on only with the master and skilled artisans but unfortunately, they are treated as just laborers or daily wagers. There are a lot of issues irking the lives and livelihood of these artisans. In this paper we are deliberating the role and contribution of designers and highlighting the plight of unsung creators of the exquisite Rajasthani crafts.

Designers nowadays are inspired and influenced by the ethnic crafts of various cultures. They strive to produce and offer collections and ranges that are often inspired by local crafts but are handled and presented in a contemporary and a modern twist. The new products that have been created are the result of suitable modifications in the existing products. Hence craft require critical intervention, support and hand holding throughout their move into markets.
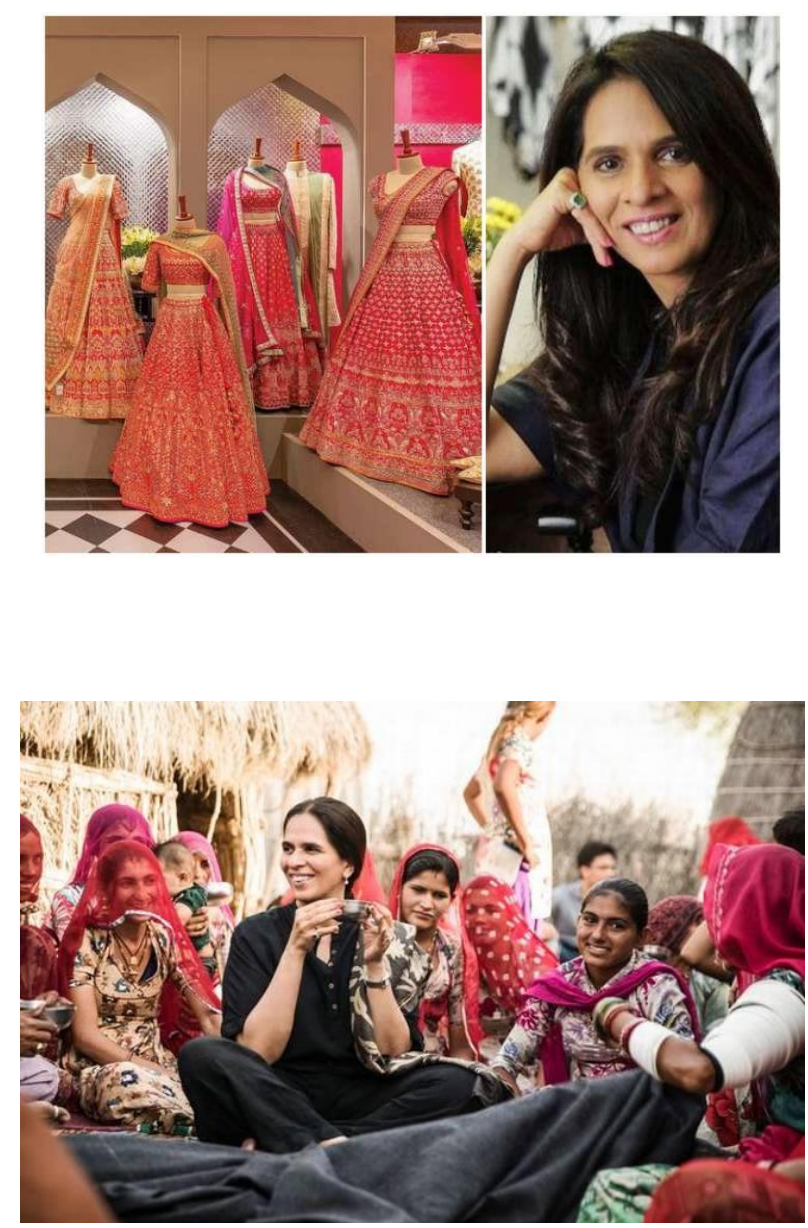

Plate 8: Designer with her work (top) and with the artisans (bottom)

(Source : https://www.indiatvnews.com/lifestyle/fashion-indian-designer-anita-dongre-says-fashion-is-no-longer-limited-totrends-457514, https://www.thehindu.com/life-and-style/fashion/the-quiet-rise-of-anita-dongre/article26469618.ece) 
These new product range introduced in the market pique the consumers' curiosity, resulting in increased production and support for craftsperson. Therefore, the designers play a vital role and are a link between the artisan and the commercial market conserving and promoting history and traditions via design interventions and solutions. Many designers attempt to combine traditional Rajasthani crafts in fusion with various modern elements churning and creating new styles. There is a need for new fashion and lifestyle products as a result of globalization and changes in social structures. Though the designers have emerged as popular in selling the trendy handicraft products yet the contribution of the hand skilled artisans cannot be ignored and remain hidden in the background. In the following paragraph the present plight and the status of the artisans is highlighted.

The artisans who were interacted with during our visits to the craft clusters were found to be lacking in education. The main reason seems that since early childhood they start practicing the craft as a helping hand to the senior members of the family. They also feel that by the end of the day it is their skill which is going to fetch them livelihood. Moreover, the number of family members are more, earning is less and they are not able to sustain education of their children to higher classes. They can't afford any assistance hence all this leads to a low education level of the artisans. They want their children to study but can't afford it. They also feel that they will lose on to their helping hands if they send their children to school.

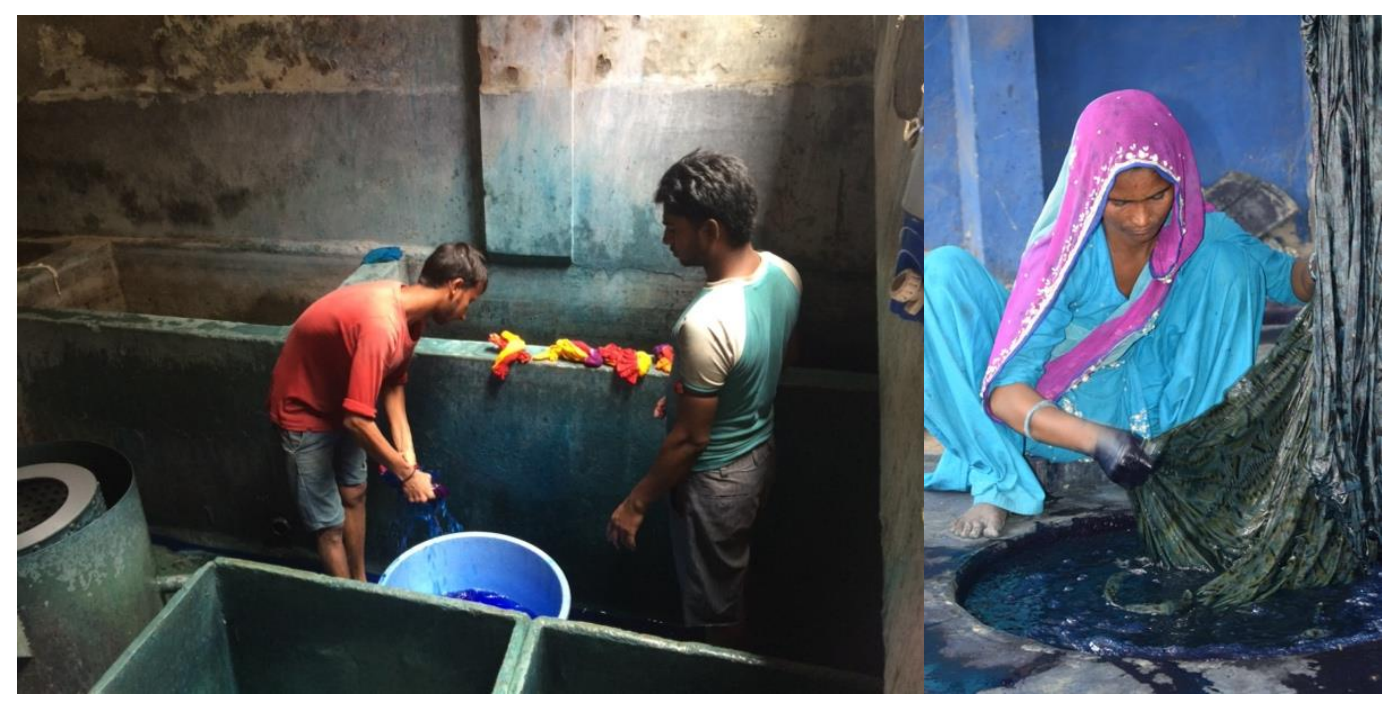

Plate 9: Artisans working in a dyeing workshops in Bagru and Sanganer, Rajasthan

They are always in a dilemma for getting orders. These artisans sustain from hand to mouth since the crafts they produce and sell is based on festivals, seasons, and market demand. There are intermediaries that offer and pass on orders while pocketing the majority of the money. As a result, the craftspeople seldom have a consistent source of income. They are constantly reliant on middlemen and hence remain at the same level whether in wages or in their status. Artisans 
involved in craft sector creating Pichwai ${ }^{1}$, Pattachitra ${ }^{2}$, Carpet weaving ${ }^{3}$, embroidery in Barmer ${ }^{4}$ also earn insufficient wages since the middlemen, such as commission agents and dealers, take a big portion of the earnings, and they live in low socioeconomic conditions. Because artisans get aid during financial difficulties, their high reliance on intermediaries for petty profits demonstrates the artisan's inability to eliminate intermediates in the marketing chain. These middlemen are also responsible for the delivery of raw materials, as well as the funding and promotion of finished products. The craftsmen of Channapatna, for example, who work on wooden handicrafts, have a low literacy level, making them reliant on intermediaries. ${ }^{5}$

We also noted that there exists a hierarchy amongst the status of various artisans. The popular ones, who have better and higher skills, frequently seek assistance of low-skilled artisans to do specific handwork activities. They provide them guidance so that they may learn the skill, but at the same time they also exploit them by paying the lowest feasible daily wages. Mohapatra and Dash discovered inconsistent supply of materials and irregular payments by master craftsmen while researching the difficulties of artisans of handicrafts in Orissa, India. ${ }^{6}$ In a research conducted by Kanungo, Sethi, and Pritam (2001) it was discovered that many times businesspeople residing on the outskirts of the craft area pretended to be traditional artisans. They buy finished goods from vulnerable craftsmen and sell them at inflated prices. ${ }^{7}$

Since Rajasthan is a hub of numerous creative arts and handicrafts, there is no dearth of artisans and craftsperson. There exists a competitive environment in skill, material, technique, wages, markets etc. It is evident that Middlemen tend to exploit this competitive climate by paying meagre amount to artisans, but these wages also differ by gender. Even in many other handicrafts like Pattachitra, female artisans are involved but their involvement is low in the primary work and they work as subordinates to their spouse, thus they have little space in developing their own

\footnotetext{
${ }^{1}$ Shruti Tiwari, and Divya Dhakad, "Design Intervention \& Craft Revival with Reference to Pichwai Paintings: A Contemporise Approach," Journal of Textile Science \& Fashion Technology, (2020):4. DOI: 10.33552/JTSFT.2020.06.000628.

${ }^{2}$ Pallavi Kanungo, Narayan Sethi, and Pritam Biswal, "Socio-economic condition, welfare schemes, and occupational structure of 'pattachitra' artisans in Odisha, India," Creative Industries Journal 14, no.1(2021), 92. 10.1080/17510694.2020.1775029

${ }^{3}$ Ishfaq Majeed and Mohammad Swalehin, "Carpet Weaving Occupation in Kashmir: An Analysis of Socioeconomic Conditions of Carpet Weavers of Pulwama District," Asian Journal of Economics, Business and Accounting 16, no1(2020), 44. Accessed December 8, 2020. https://www.researchgate.net/publication/342814753_Carpet_Weaving_Occupation_in_Kashmir_An_Analysis_of_ Socio-economic Conditions of Carpet Weavers_of_Pulwama District

${ }^{4}$ Garima Tiwari and Radha Kashyap, "Assessing socio economic conditions of embroidery artisans in Barmer," International Journal of Home Science 5, no.2 (2019), 28,230, accessed January 5, 2021. https://www.homesciencejournal.com/archives/2019/vol5issue2/PartD/5-2-39-468.pdf

${ }^{5}$ Bala Koteswari and Sudha N Natesh, "A Study on Marketing Opportunities and Challenges of Wooden Handicraft Products: With Special Reference to Channapatna Artisans," (Paper presented at two days international conference on Business Dynamics and sustainable development, Bengaluru,2-3 March,2020), 66. https://www.researchgate.net/publication/344014265

${ }^{6}$ Sanjay Mohapatra and Manjusmita Dash," Problems Associated with Artisans in Making of Handicrafts in Orissa, India,” Management Review: An International Journal 6, no.1(2011), 61. Accessed January 24, 2021. https://higherlogicdownload.s3.amazonaws.com/INFORMS/a19154ba-c5e4-4a42-af420c6b23c694b8/UploadedImages/MRIJ6(1)2011(3).pdf

${ }^{7}$ Pallavi Kanungo, Narayan Sethi, and Pritam Biswal, "Socio-economic condition, welfare schemes, and occupational structure of 'pattachitra' artisans in Odisha, India," 90.
} 
creative talents. It impedes their decision-making process and they lack mobility. ${ }^{8}$ It also impacts the wages earned by women artisans. Women artisans have little control over the distribution and marketing of crafts, which exacerbates their inequality within the sector. ${ }^{9}$

Moreover, since the lower category artisans are always dependent on others for market linkages, they never develop their own public relation skills and networking. For years, they remain as invisible workers. This lack keeps them always unseen, unheard and unknown. And someone else becomes the face of their skill and craft. On the contrary the upper category of these artisans faces and meet the same fate when they work just as skilled laborer for the commercial designers. Again, they remain unheard, unseen and unsung because the designer's name tag and label is highlighted with their hand, hard work and skill in the background.

Because they are educationally behind and lack marketing abilities, these artisans are not exposed to the most recent technological developments in their crafts. They continue to use timeconsuming procedures that have been used for a long time. Investment in technology necessitates money neither the buyers invest any money in the technological advancement of the artisan, nor are the artisans capable of investing money in the same. The lack of capital in the hands of artisans, to upgrade the craft and their craft practices, is a significant impediment to the craft's growth. It becomes difficult to develop innovative handicrafts with their own initiatives as craft producers who have inherited traditional skills fail to adopt new and innovative ideas. They are aware of advertising and promotional strategies, but are unable to encash them due to severe financial inability and a lack of interest and sponsorship. Many a times the artisans fail to tap the market trends and preferences of the consumers. Therefore, they are perpetually facing such challenges and need handholding of the vendors or the designers to know what is the requirement of the market.

Young generation of artisans are not interested in working in the handicraft sector because industry since it is laborious and unappealing owing to the use of obsolete tools, high taxes, and a rigorous government system in dealing with the difficulties that handcrafters face. Furthermore, the benefits of pursuing handicrafts so are minimal with meagre earnings which does not justify their cost of living. This is a significant loss to our culture since it is not being passed on from generation to generation. ${ }^{10}$

The need of the hour is to uplift and upgrade these unseen and unknown faces before the craft further declines. These skilled hands need to be held and motivated into the right direction. Whenever the designers work with these artisans, the names of these skilled artisans should be highlighted. State emporiums, designers and various platforms within our society should shoulder the responsibility to encourage these artisans to educate and uplift their families. Artisans should understand customer taste and trends as they can't create in isolation, hence it is essential to update artisans about marketing information. NGOs, Government emporia selling artisans products can regularly communicate to the artisans about what is the demand of

\footnotetext{
${ }^{8}$ Kanungo, Sethi, and Biswal, "Socio-economic condition," 98.

9 Timothy J Scrase, "Precarious production: Globalisation and artisan labour in the Third World," Third World Quarterly 24, no.3(2003), 451.

${ }^{10}$ Rose Ignas Makyao, "Challenges facing handicraft businesses in implimenting promotion strategies for their products," 55.
} 
customers or the regular feedback from the customers for further improvisation and diversification in their creation and if possible some workshops can be organised for the benefit of the crafts and craftspeople. The artisan community and the tourism industry/department can work together ${ }^{11}$ and authorities can assist craftsperson in reaching their intended customers and in introducing transparency to the craft cluster. Creating a tourist concept booklet or launching a monthly magazine where craftsmen may contribute ideas. ${ }^{12}$

These artisans need to be aware of various marketing opportunities for them to explore as well as the channels available for them that is a help from the government. Many of the artisans try to give their products to others to sell it in the market. Along with creating awareness programmes regarding schemes and programmes to support financially which are established for the artisans and training programmes to understand and prepare the products according to the trends in the handicraft market-follow up of these schemes and programmes is essential. Many times, artisans get to know about the schemes, but they don't know where to go or who to approach to take advantage of these schemes and programs, and as a result, such programs fail or fizzle. Various stakeholders like government and various related ministries, trainings institutions, financial institutions, tax authorities should come together to work out policies or schemes or programmes to uplift this sector.

Although the efforts and intervention of Government, NGOs and designers have given a new lease of life to these unnamed artisans but a still lot needs to be done to restore and revive their lost glory. The main thrust of such efforts is on up gradation, product design development, artisans' trainings, trendy colour palettes etc. This is mainly to innovate and generate newer product ideas out of the existing craft traditions and techniques. These unseen, unheard, unnamed and the matchless and unsung artisans are indeed the real heroes who lend all the glamour and glimmer to the gorgeous handlooms and hand crafted textiles of Rajasthan .

\footnotetext{
${ }^{11}$ Yashu Jaisingh, “Artisan Entrepreneurship and Community-Based Tourism Nexus - Indian Art \& Craft Renaissance,” (Master's Thesis, Auckland University of Technology, 2020), iii. http://hdl.handle.net/10292/14009

12 Kanungo, Sethi, and Biswal, "Socio-economic condition," 102.
} 


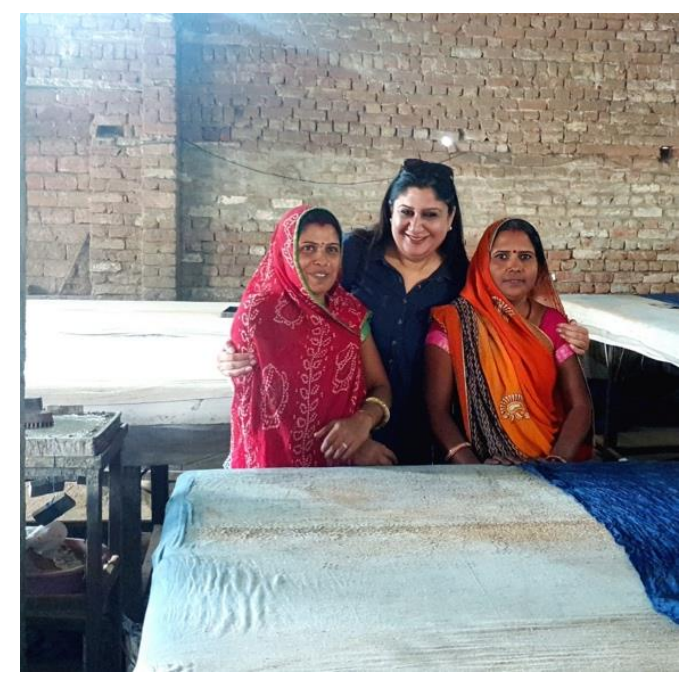

Plate 10: Lending unconditional support to these unseen unheard unnamed heroes

\section{Bibliography}

Kanungo, Pallavi, Narayan Sethi, and Pritam Biswal. "Socio-economic condition, welfare schemes, and occupational structure of 'pattachitra' artisans in Odisha, India." Creative Industries Journal 14, no.1(2021), 81-106. 10.1080/17510694.2020.1775029

Koteswari, Bala, and Sudha N Natesh. "A Study on Marketing Opportunities and Challenges of Wooden Handicraft Products: With Special Reference to Channapatna Artisans.” Paper presented at two days international conference on Business Dynamics and Sustainable Development, Bengaluru, March 2-3,2020).

https://www.researchgate.net/publication/344014265

Majeed, Ishfaq, and Mohammad Swalehin. "Carpet Weaving Occupation in Kashmir: An Analysis of Socio-economic Conditions of Carpet Weavers of Pulwama District." Asian Journal of Economics, Business and Accounting 16, no1(2020), 41-49. Accessed December 8,2020. https://www.researchgate.net/publication/342814753_Carpet_Weaving_Occupation_in_Kashmir _An_Analysis_of_Socio-economic_Conditions_of_Carpet_Weavers_of_Pulwama_District

Makyao, Rose Ignas. " Challenges facing handicraft businesses in implimenting promotion strategies for their products.” Master's thesis, Open University Of Tanzania, 2013. http://repository.out.ac.tz/id/eprint/969

Mohapatra, Sanjay, and Manjusmita Dash. " Problems Associated with Artisans in Making of Handicrafts in Orissa, India.” Management Review: An International Journal 6, no.1(2011):5681. Accessed January 24, 2021. https://higherlogicdownload.s3.amazonaws.com/INFORMS/a19154ba-c5e4-4a42-af420c6b23c694b8/UploadedImages/MRIJ6(1)2011(3).pdf 
Scrase,Timothy J. "Precarious production: Globalisation and artisan labour in the Third World." Third World Quarterly 24, no.3(2003), 449-461. https://doi.org/10.1080/0143659032000084401.

Tiwari, Garima, and Radha Kashyap. "Assessing socio economic conditions of embroidery artisans in Barmer." International Journal of Home Science 5, no.2 (2019), 228-231, accessed January 5, 2021. https://www.homesciencejournal.com/archives/2019/vol5issue2/PartD/5-2-39468.pdf

Tiwari, Shruti, and Divya Dhakad. "Design Intervention \& Craft Revival with Reference to Pichwai Paintings: A Contemporise Approach." Journal of Textile Science \& Fashion Technology (2020), 1-7. DOI: 10.33552/JTSFT.2020.06.000628.

Yashu Jaisingh. " Artisan Entrepreneurship and Community-Based Tourism Nexus - Indian Art \& Craft Renaissance.” Master's Thesis, Auckland University of Technology, 2020. http://hdl.handle.net/10292/14009. 